\title{
The Mind of the Hungry Agent: Hunger, Affect and Appetite
}

\author{
Michele Davide Ombrato ${ }^{1}$ [] $\cdot$ Edgar Phillips $^{2}$
}

Accepted: 29 October 2020 / Published online: 8 December 2020

(c) The Author(s) 2020

\begin{abstract}
The aim of this paper is to provide an account of how hunger motivates us to seek food and eat. It seems that the way that it feels to be hungry must play some role in it fulfilling this function. We propose that hunger is best viewed as a complex state involving both affective (viz., hedonic) and somatic constituents, as well as, crucially, changes in the way in which the hungry agent's attention is deployed. We argue that in order to capture the distinctive way in which hunger motivates we need to articulate the relations amongst such components. The resulting account explains how hunger as an aversive affective reaction to a state of need motivates us specifically to eat and not to just to rid ourselves of the unpleasant sensations associated to it. We suggest, however, that there is more than this to the overall affective experience of the hungry agent, because hunger ordinarily facilitates the elicitation of other, positive affective reactions such as interest and appetite, and recruits them to further its function.
\end{abstract}

Keywords Hunger $\cdot$ Appetite $\cdot$ Affective reactions $\cdot$ Attention $\cdot$ Emotions $\cdot$ Motivation

\section{Introduction}

The primary biological function of hunger is to motivate us to seek food and eat. A tempting first pass at a philosophical account of hunger might then be to say that being hungry is simply a matter of being disposed to engage in food-seeking and -consuming behaviour. This suggestion, however, succumbs to the slightest scrutiny. Even though being hungry clearly does involve being disposed to eat, it seems that we may be so disposed without being hungry: we may want to eat, for instance, in order to gain weight, or because the food before us is especially appealing, or out of boredom.

The authors are listed alphabetically and equally contributed to this paper. Sections 3 and 4 draw on ideas from chapter 2 of Michele Ombrato's doctoral dissertation. For comments and discussion, we thank Fabrice Teroni, Matthew Soteriou and two anonymous reviewers. Michele Ombrato gratefully acknowledges support of his work by a grant from the Schmidheiny Foundation.

Michele Davide Ombrato

michele.ombrato@unige.ch

1 Department of Philosophy, University of Geneva, Swiss Centre for Affective Sciences, Campus Biotech, 9 Chemin des Mines, Geneva, Switzerland

2 Thumos Research Group, Swiss Centre for Affective Sciences, Campus Biotech, 9 Chemin des Mines, Geneva, Switzerland
What is it, then, that is distinctive about being hungry and about being motivated by hunger to eat? A natural thought is that hunger feels a certain way that other states of being motivated to eat do not, and that hunger motivates us to eat in virtue of its feeling that way. If this thought is correct, accounting for how hunger motivates requires accounting for its experiential dimension, and the connection between the hungry agent's experience and her food-seeking and -consuming behaviour.

Some common-sense observations might seem to support a fairly simple account of how hunger motivates. First, the hungry person typically experiences a kind of discomfort: hunger involves distinctive unpleasant sensations. Indeed, in cases of extreme deprivation, hunger is viewed as a form of abject suffering. Second, the discomfort is normally alleviated by means of eating. Hence the simple account: we don't like experiencing discomfort, so when we feel hungry, we want to eat. Further observations, however, cast doubt on this account. For one thing, the experience associated with being hungry is not always negative; for instance, we are typically pleased to be hungry if we have a good meal to look forward to. In such cases, feeling hungry is often inextricably intertwined with a host of positive affective phenomena: feelings connected to the anticipation of satisfaction as well as emotional reactions such as interest in and excitement about food. Relatedly, it seems that, even if 
we can conceptually distinguish hunger from what we call appetite, that is, the felt desire to eat for eating's sake, the two ordinarily come together: we look forward to eating not merely as a way to alleviate the unpleasant sensations associated to hunger but as something inherently enjoyable. The presence of this desire in the mind of the hungry agent seems to be more than mere coincidence. Finally, and more fundamentally, even if we restrict our focus to the negative aspects of the experience associated to being hungry, the connection between hunger's negative hedonic character and its character as a motivation needs clarification. Should we think of hunger as discomfort in order to alleviate which we are motivated to eat? Or might we instead construe such discomfort as already implicating something motivational, so that to understand being hungry as a way of being discomforted is to understand it as a way of being motivated?

In this paper, we show how developing this latter suggestion can provide an account of how hunger motivates that is free from the problems of the simple account. We will argue that the experiential dimension of hunger is best viewed as affective in nature, and more specifically, that it involves a dynamic complex interplay of negative and positive hedonic feelings. Such hedonic feelings motivate in virtue of their inherently punishing and rewarding phenomenology, which crucially involves specific changes in the way the hungry agent's attention is deployed.

Our discussion will proceed as follows. First, in §2, we consider a seemingly straightforward strategy for accounting for hunger's motivational role. On this approach, there is nothing distinctive about the hungry agent's motivation to seek food: it is simply an instance of ordinary rational motivation and thus does not itself need to be characterised in reference to the distinctive phenomenal characteristics of feeling hungry. What distinguishes the motivation associated with hunger is just that in this case our reason for eating is that it will rid us of hunger's unpleasant sensations. We argue that this model makes the relationship between feeling hunger and eating implausibly instrumental and fails to capture the urgency characteristic of the phenomenon.

These aspects of hunger, we argue in $\$ 3$, suggest that feeling hungry involves a felt need or urge to eat that is inherently motivating. This raises a question about the connection between the urge and the kinds of somatosensory aspects of feeling hungry to which the previously considered account appealed. The standard approach to hunger and other 'drive-based' affective reactions-e.g., thirst, fatigue and other physical cravings-is to characterise this connection at the subpersonal level: there are neurological mechanisms that connect negatively valenced representations of given deficiencies, such as, for example, representations of undernourishment, with urges or impulses. To be hungry is thus to be subject to certain specific sensations and urges or impulses that happen to be neurologically coupled. This sort of account is, we suggest, incomplete in that it says nothing about either the phenomenology of the urge to eat nor about how this urge is connected with the unpleasant sensations of hunger at the personal, experiential level. In $\S 4$ we articulate that connection by appealing to attention as mediating between the two components, developing our account by analogy with the similar role that attention plays in reflexive pain reactions.

This account satisfies the main aim of the paper: it explains how hunger motivates us, through its phenomenology, to eat. Nonetheless, as we suggest in $§ 5$, the appeal to a felt need or urge is not enough to capture the complexity of the way we are ordinarily motivated when hungry. In order to do that we need to consider hunger's relation to further affective reactions, more specifically ones with a positive, attracting, rather than aversive, character. In particular, we argue that hunger facilitates the elicitation of appetite, a felt desire for food or attraction to the prospect of eating, and that such phenomenon is recruited by hunger to further its motivational role, so that, ordinarily, we are at once driven by hunger and drawn by appetite. This dual character of the hungry agent's motivation to eat, as we show in $\S 6$, can go a long way to explaining the variable hedonic features of hunger and eating.

\section{Hunger and Rational Motivation}

It is natural, as we have said, to think that hunger motivates us to eat in virtue of the way it feels. We will later present an account on which the motivating character of hunger is indeed inseparable from its phenomenal character. This claim might, to some, appear too strong. There are, after all, many motivational states of which this is not the case, such as one's desire to cross the road when on the way to the station, or a parent's long-term standing desire for their children's success (Smith 1987, p. 48). We might conclude, with Anscombe, that while 'desire' can in everyday language be used for something we feel- "the prick of desire"- this sense of the word is "not of any interest in a study of action and intention" (Anscombe 1963, pp. 67-70).

We might, if moved by this line of thought, prefer a more parsimonious approach to how hunger motivates, on which the felt dimension of hunger, whilst being in itself motivationally inert, gives the hungry person a reason to eat, a reason on the basis of which they are motivated to eat. The hungry agent's motivation to eat is, on this account, simply an exercise of practical intellect: an instance of our general capacity to be moved to act by reasons. Assuming this form of motivation is sufficiently well understood, we need only explain how hunger gives us reason to eat. A natural account suggests itself: the feeling of hunger gives one a reason to eat because being hungry involves unpleasant sensations that, 
as such, we have reason to alleviate. We are thus motivated to eat, when hungry, because we know that such unpleasant sensations can be alleviated or removed by means of eating. This seems to be in line with how Scanlon proposes to understand thirst:

"What does [thirst] involve? First, there is the unpleasant sensation of dryness in my mouth and throat. Also, there is the thought that a cold drink would relieve this sensation and, in general, feel good. I take this consideration, that drinking would feel good, to count in favor of drinking. It is this future good-the pleasure to be obtained by drinking-that makes it worth my while to look for water. The present dryness in my throat give[s] me a reason to believe that a drink of water in the near future will give this particular pleasure. But the motivational work seems to be done by my taking this future pleasure to count in favor of drinking." (Scanlon 1998, p. 38, italics added).

This account fits with Scanlon's general attempt to understand motivation in terms of the agent's recognition of reasons for action. His attempt to fit the felt aspect of states like hunger and thirst within that framework is admirably neat, but it seems, in a number of respects, not quite right.

The first and most glaring issue with this treatment of hunger is that it seems implausibly intellectualising. Hunger, on this sort of account, essentially involves thoughts about pleasure and discomfort as such-and perhaps, in Scanlon's version, even thought about reasons as such. An obvious challenge to this sort of account is that hunger seems perfectly capable of motivating animals to seek food and eat, including many species of animals to which we would hesitate to attribute thoughts about pleasure and discomfort, let alone thoughts about reasons. Of course, we are concerned here to account for how hunger motivates us, human agents, and we do not mean to assume that human and animal motivation are the same in every respect; nonetheless, there is something puzzling about the idea that feeling hungry is sufficient to motivate non-human animals but is motivationally inert in us unless coupled with thoughts about reasons.

Another problem with the account in question, more pertinent to the aims of this paper, is that it fails to capture a crucial aspect of the phenomenology of being hungry. The account suggests that being hungry motivates us to eat because we know that by means of eating, we can relieve ourselves of unpleasant sensations. We recognise these sensations, know that eating will bring them to an end, and so we eat. This makes the hungry agent's motivation to eat look implausibly instrumental: we eat as a means to alleviating unpleasant sensations.

Scanlon might here point out that his account appeals not only to the alleviation of unpleasant sensations, but also to future pleasures. And he might argue, with Wilson $(1972$, p. $184 n$.), that to say that something one does for pleasure is something one does "as a means to enjoyment" is "a purely verbal manoeuvre": doing something because you like it or enjoy it is "importantly different from doing something as a means to a further end." However, the pleasure in question in the Scanlonian model seems to be, primarily, the pleasure of relief from present discomfort. This is a distinct pleasure from that of intrinsic enjoyment of an activity: eating gives us pleasure in Scanlon's account not in itself but only through its effects. The problem with this is that the pleasure of relief is extrinsic to, and thus, in principle, separable from, the activity of eating.

To see this point, consider that the account makes the hungry agent's motivation to eat structurally akin to the desire you might have, when suffering a headache, to take a painkiller. In that situation, you experience discomfort and know you can take steps to relieve it. If the painkiller works well and quickly enough, we may well characterise your relief as a pleasure. Crucially, though, the specific action you take to attain such pleasure is merely incidental: if you could achieve the same relief by other means then you would, all else being equal, be indifferent between those means and the pill. Now, being hungry does sometimes motivate us to eat in this kind of way, that is in virtue of an extrinsic connection to rational motivation. We sometimes notice that we are experiencing unpleasant or otherwise undesirable symptoms of hunger, such as pangs, fatigue, light-headedness, or getting 'hangry', and decide that we should eat to alleviate these symptoms. We might, being sophisticated as we are, learn that other methods-appetite suppressant drugs, perhaps-are available for removing or reducing these symptoms when we find them inconvenient, and we may, particularly if we are preoccupied with something else and not interested in eating, prefer such means to eating. Cases of this kind are clearly atypical, however, and is it striking that Scanlon's account fits them especially well. There is a difference between, on the one hand, noticing undesirable symptoms of hunger and being rationally motivated to alleviate them, and on the other, simply feeling hungry. Hunger bears an internal relation to food-seeking and eating that Scanlon's picture fails to capture: hunger, in its nature, directs us, compels us, specifically to seek food and eat, and not just to seek to rid ourselves of unpleasant sensations by whatever means available.

Another aspect that seems missing from Scanlon's model is hunger's urgency. Maybe the feeling in your stomach when you're hungry doesn't feel great, but except in extreme cases it is far from the level of an intense pain. Yet very often when hungry we simply cannot stop thinking about food and eating, so that we may find it very difficult or even impossible to do anything else requiring attention until we have eaten. Feeling hungry seems to constrain our attention in a way that simply being subject to an unpleasant sensation 
does not, and this seems to impart to our motivation to eat its distinctive felt urgency.

To be fair to Scanlon, he does acknowledge that something might be missing from his picture. He voices this worry, again discussing thirst, as follows:

"[It may seem that in] addition to the dryness in my throat, the future pleasure brought about by drinking, and my judgment that this pleasure is desirable, there is the fact that I feel an urge to drink. This, it might be said, is what my desire consists in." (Scanlon 1998, p. 38, italics added).

An urge, whatever exactly that is, might be just the kind of thing that has the features we are looking for: a kind of felt urgency and an internal relation to a specific course of action. Scanlon, however, is not impressed by the suggested appeal to urges, as "the idea of a mere urge to act ... does not fit very well with what we ordinarily mean by desire." The desire to drink, he insists, "is not merely a matter of feeling impelled to do so; it also involves seeing drinking as desirable" (Scanlon 1998, p. 38). We do not disagree with Scanlon on this point, although we would question his appeal to thought about reasons in characterising the 'seeing as desirable' that's involved. Relatedly, we want to challenge the apparent assumption that 'mere' urges, if they do not amount to "what we ordinarily mean by desire", are of little or no interest in thinking about motivation. What our discussion of hunger to this point seems to suggest is precisely that felt urges may be central to how hunger ordinarily motivates. Urges such as those involved in thirst, hunger, fatigue, sexual arousal and various physical cravings, such as the cravings of addiction play a real and important motivational role that many authors interested in motivation by reasons have, we think, been too eager to dismiss.

\section{Hunger as Felt Urge or Affective Reaction}

The problems with the above rationalistic and instrumental account of how hunger motivates suggest that we should take seriously the idea that feeling hunger, as opposed to merely noticing symptoms of hunger, already involves motivation: the feeling of hunger is inherently motivating. To understand hunger in this way-rather than as a mere sensation-is to understand it as what we will call an affective reaction. Before turning to our specific proposal, it will be helpful to introduce a number of widely accepted preliminary assumptions and some useful terminology.

Affective reactions, as we understand them, form a broad mental category including disparate phenomena, such as, for instance, reflexive pain reactions, sensory pleasure, pleasure in activity, hunger, fatigue, sexual arousal and emotional reactions such as (felt or episodic) joy, fear, anger, shame, admiration, and so on. All these disparate phenomena are classified together as affective because they involve changes in affect, that is, positive or negative hedonic feelings and, relatedly, felt states of attraction or aversion. They are affective reactions in that they are initiated by their specific elicitors or triggers independently of agential control: reflexive pain reactions and sensory pleasure, for example, are initiated, respectively, by noxious and pleasurable stimulation; thirst, hunger, fatigue and physical cravings by various homeostatic disturbances; emotional reactions by (cognised) 'concern-relevant' - i.e. personally or biologically significant-events, objects or situations. ${ }^{1}$ We shall assume that affective reactions are intentional phenomena and, relatedly, complex episodes: as we will see later on in more detail, they involve both affect and the sensations or cognitions from which they inherit their 'directedness' or intentionality. Following a widely accepted terminology, we shall refer to these sensations and cognitions as the bases of the affective reactions. ${ }^{2}$

Within the class of affective episodes based on sensations, we can further distinguish cases where the sensations are caused exogenously, that is by external stimuli, or, as in the case of the affective reaction with which we are specifically concerned in this paper, namely hunger, endogenously, that is by the workings of physiological mechanisms which preserve homeostasis. We may thus distinguish three kinds of affective reactions: sense-based reactions such as reflexive pain reactions and sensory pleasure; cognition-mediated affective reactions, including emotional reactions such as fear, anger, shame, but also affective interest and affective desiring; and, finally, drive-based affective reactions like thirst, hunger and other physical cravings.

It is widely agreed that affective reactions involve motivation: they impel, and in some cases even compel goaldirected cognition and behaviour. The motivating dimension of affective reactions is indeed one of their essential properties, as we should expect given the plausible hypothesis that the primary biological function of such phenomena is to motivate us to deal or cope with the 'demands' of the affect-eliciting situation ${ }^{3}$-for example (potential) damage to some body part, homeostatic disturbances, or, in the case of properly emotional reactions, 'concern-relevant' situations (for example cognised threats to our physical and personal integrity in the case of fear).

\footnotetext{
1 The view that emotional reactions differ from other affective reactions in that their occurrence requires some form of cognition of the reaction's object is the central premise of all broadly cognitive theories of emotion and is the current orthodoxy in philosophy of emotion and affective sciences. See Reisenzein and Schönpflug (1992) on the origin of this idea in Brentanian philosophical tradition.

2 See Deonna \& Teroni (2012) and Mulligan (2007) for discussion of the claim that affective reactions, and emotional reactions in particular, inherit their intentionality from their bases.

${ }^{3}$ Cf. e.g., Scarantino (2005); Tomkins (1995); Frijda (1986; 2007).
} 
Affective reactions owe their motivating dimension to their affective component, the inherently rewarding or punishing hedonic feelings. ${ }^{4}$ At a certain level of description, these feelings are common to all affective reactions: all positive affective reactions involve a felt attraction, and all negative affective reactions a felt aversion. ${ }^{5}$ However, each specific affective reaction motivates distinctive kinds of goal-directed behaviour. This raises the question how the motivating power of affect obtains this goal-directedness. Scanlon is thus right to look for something that mediates between the somatosensory component of states such as thirst and hunger and the specific behaviour they motivate; he is wrong, however, to think that this forces us to invoke thoughts about sensations as such to play that role.

In order to capture the specifics of the way in which being hungry motivates us to act, we suggest, we need to understand the relation between affect and the somatosensory components to which hunger owes its intentionality, namely the various sensations associated with the workings of physiological mechanisms preserving homeostasis. Being hungry involves various largely unpleasant sensations associated with physiological states of need or deficit. More specifically, when glucose levels fall, a cascade of hormonal alterations produces autonomic and visceromotor activation we experience as feeling hungry. ${ }^{6}$ Because of its dependency on such homeostatic mechanisms, hunger motivates cognition and behaviour specifically aimed at reducing the associated deficiencies. But how, at the personal level of

\footnotetext{
4 The idea that affect is inherently and distinctively motivational is defended, among others, by Johnston (2001) and Tomkins (1995). See also Melzack \& Casey (1968), Grahek (2001) and Soteriou $(2013 ; 2018)$ on the motivating dimension of pain as affective in nature.

5 Talking about positive and negative hedonic feelings, on the one hand, and felt states of attraction and aversion, on the other, are two ways of talking about the same phenomenon at distinct levels of description, that is, respectively, as experiential occurrences making up the agent's stream of conscious experience and conditions of the agent obtaining in virtue of such experiential occurrences. This way of thinking the relation between occurrent, experiential and stative aspects of the mind is part of the detailed account of such relation proposed by Soteriou (2013) as an account of the ontology of the mind that fit the phenomenology of a variety of psychological phenomena.

${ }^{6}$ According to recent research in the medical sciences, in a glucosedepleted state, the peptide hormone ghrelin is secreted, triggering gastric wall contractions associated with feelings of hunger such as the distinctive 'empty' sensation; see e.g. Date et al. (2000); Gnanapavan et al. (2002); Kim et al. (2003); Kojima et al. (1999); Toshinai et al. (2001). Other hormones that are secreted when glucose levels drop, such as cortisol and glucagon have long been associated to other unpleasant sensations like nausea, fatigue, weakness, dizziness and the like; see e.g. Baynes \& Dominiczak (2014), Christensen, Alberti and Brandsborg (1975); Corrall et al. (1983); Heller, Herbert, Macdonald et al. (1987).
}

description, do the somatosensory and affective components of hunger interact to motivate such behaviour?

Not much theoretical effort has been put into articulating this relationship; the common tendency is to articulate it at the subpersonal level. This is perhaps in part because states like hunger, in the philosophical literature, are typically discussed for merely contrastive purposes, to distinguish them from other more cognitively sophisticated affective reactions like emotions or affective desiring. An example of this approach is Prinz (2004). Prinz, like us, takes it that in order to understand the distinctive conative features of hunger we need to distinguish hunger as an urge from emotional reactions understood as 'motives': the difference is, according to him, that motives provide reasons for action, while an urge impels or commands us to act. Prinz recognises that hunger involves both somatosensory and motivational components, but he views the relation between them as a hard-wired coupling relation that obtains at the subpersonal, neurological level:

"Hunger actually commands us to eat, it is associated with cellular response in the lateral hypothalamus, which regulates eating behavior. Stimulation in this region causes us to eat, and damage causes us to stop eating. If a person simply had a negatively valent representation of her undernourishment, say an unpleasant sensation of an empty gut, we would not necessarily say she was hungry ... hunger is a negatively valent representation of undernourishment coupled with an impulse to eat." (194).

If we wish to take seriously the thought that hunger motivates in virtue of how it feels, though, we cannot be satisfied with this account. The connection between feeling hungry and having an urge to eat is not, from the hungry agent's perspective, a mere coincidence; they are, so to say, experientially unified. To understand this, we suggest, we need to understand how attention mediates between the somatosensory and the affective component of hunger. In order to do this, we shall exploit a comparison with a kind of affective reaction that has received a good deal more attention in philosophy, that is, pain, or more precisely reflexive pain reactions. ${ }^{7}$

\footnotetext{
7 We prefer to speak of 'reflexive pain reactions' rather than 'pain' in order to exclude chronic pain, that is, pain that is not elicited by noxious stimulation.
} 


\section{Affect, Attention and Motivation}

Our suggestion is that the motivating power of affective reactions is intimately connected with their power to consume attentional resources, and specifically to do so by drawing our attention to the sensations or cognitions that constitute the bases of affective episodes. To illustrate this idea, we will first explain how attention plays this role in the case of reflexive pain reactions.

First, note that subjects of such reactions feel impelled or compelled to attend to certain located painful sensations in a way in which they wouldn't if the sensations weren't painful. A painful sensation is typically relatively difficult to ignore: it tends to be more or less obtrusive, depending on its extent, quality and intensity, and depending on how it compares with the other sensations and cognitive processes with which it has to compete, at the time it occurs, for our limited attentional resources. We might think that what compels attention is simply the inherent salience of the located somatic sensations. However, it seems that what draws our attention to these sensations is not their extent, quality or intensity qua sensations, but rather their painfulness. ${ }^{8}$ Consideration of so-called dissociation syndromes in the human experience of pain, especially pain asymbolia (Grahek 2001; Soteriou 2013) confirms this intuition: conscious awareness of the located sensations doesn't, in the absence of any aversion, "move the mind in any way" and is all too easily ignored (Grahek 2001, pp. 72-73). On the other hand, when one is in a state of pain because of some located painful sensation, one's attention is not occupied by one's being in pain as some global, unlocated pain or suffering, as may be the case, for example, in exhaustion or emotional suffering, and one's experience is clearly different from that of other global, unlocated unpleasant sensations such as those generated, by, for instance, certain tastes, sounds, or colours (Sherrington 1900, pp. 968-967). To focus on one's being in pain is to focus on certain precise sensations as located in one's body and as having distinctive 'painful' qualities, such as being pulsing, cutting, drilling, stabbing, or throbbing, as well as their extents and intensities. This distinction is illustrated by another dissociative syndrome. This syndrome is characterised by "loss of pain sensation with preserved pain affect" (Ploner et al. 1999, p. 211) and is thus the 'converse' of pain asymbolia. Though the patient in some sense feels they are in pain, they are unable to localise exactly the site of the noxious stimulation, to register its temporal properties, to evaluate its intensity and to qualify it in any way except as generally unpleasant (Grahek 2001, pp. 100-104). The

8 Although Soteriou is not specifically concerned with the role of attention, the following discussion owes much to his (2013) discussion of the structure of pain. distinctive contributions of the affective and somatosensory components of reflexive pain reactions thus seem to be this: while the former contributes the aversive character of pain, the latter provides information about its spatial and temporal character, its intensity and painful qualities.

In light of this analysis, we may say that while the affective component of the reaction determines the persistence or continuation of our attentional engagement, the somatosensory component determines the direction of attention. This modification of the way in which our attention is deployed during affective reactions is, we suggest, what imparts urgency to the behaviours that affective reactions motivate ${ }^{9}$ : during affective reactions it seems to the subjects that their capacity to engage in any activity requiring attentional resources is and will continue to be impaired until they have coped with the demands of the affect-eliciting situation - for instance, in reflexive pain reactions, until they have protected the potentially damaged body part, or, in thirst or hunger, until they have drunk some water or eaten some food. In this sense, affective reactions are 'disturbances' or 'perturbations' that disrupt, interrupt or prevent other activities that would require attentional resources (cf. Frijda 1986; 2007; Mandler 1975).

In both pain and hunger, there is an aversion towards some bodily condition, but in virtue of the internal relation between such bodily conditions and our suffering or discomfort as mediated by attention we are not motivated to make our suffering or discomfort cease by any means available, but rather in certain specific manners. This point is nicely articulated in Soteriou's (2013) discussion of the relationship between one's having painful located sensations and one's being in pain or suffering:

"The kind of located sensation-event that is occurring feels to the subject to be one that couldn't occur without her being aware of it and without her being in pain - without that part of her body hurting. So, it feels to the subject as though it is not possible to stop the unpleasant effect of the occurrence of the located sensation-event without stopping the occurrence of that located sensation-event. Therefore, the subject won't simply be inclined to avoid the unpleasant effects of the occurrence of the sensation-event. The subject's natural inclination will be to protect herself from whatever it is that is causing the occurrence of the located sensation-event, and this will often require protecting the body part where she feels the sensation-event to occur." (Soteriou 2013, pp. 75-76, italics added).

\footnotetext{
9 The link between attention and felt urgency is highlighted by Nash (1989)'s account of emotional reactions.
} 
This internal relation between the somatosensory and the affective component explains why during pain we feel an urge to protect the body part where the painful sensations are localised. Analogously, it may explain, we suggest, why in hunger, we feel an urge to eat, that is, to remedy the situation that is causing the occurrence of the unpleasant sensations of hunger, and not an urge to seek to rid ourselves of such unpleasant sensations by any means available.

This view, unlike a view on which thoughts about sensations mediate between sensations and the motivated behaviour, can account for the variable strength of our motivation. The more intensely we are affected-the more we sufferthe more we feel that our attentional engagement with the affect-eliciting situations gets close to non-optional or compelled. This explains why the behaviour motivated by intense pain or hunger often takes precedence over other courses of action, even when we have strong reasons to pursue other goals such as winning the match or losing weight: when the affective reaction is strong enough, we cannot attend to the thought and action required to pursue those goals until the affect-eliciting situation has been addressed.

\section{The Desire for Food}

This account of hunger as an urge is enough, we think, to explain how hunger can move us to eat in virtue of how it feels, without being subject to the problems faced by an account on Scanlon's model. However, we also think that there is more to be said. As indeed Scanlon also recognises, what the concept of an urge doesn't capture is the positive attraction we feel towards eating, the anticipated pleasures of satisfying our hunger. If we are interested not just in hunger as a state of deprivation but in the motivational structure that is ordinarily at play in the mind of the hungry agent, and also in the character of the overall experience of hunger-feeling hungry, as opposed to just feeling hunger-we need to account for the role of this felt attraction.

It is widely acknowledged that the motivation to seek food and eat may have diverse causes, including not only homeostatic disturbances but also external stimuli, such as the taste, smell or sight of food, as well as food-related thinking and imagining. In the medical sciences, it is common to distinguish the homeostatic causes from what we may call situational or cognitive causes. Particularly if we accord the bases of affective reactions the kind of role envisaged in our account of hunger as an urge, this distinction naturally leads to the view that there exist two distinct species of the desire for food, which differ not only in their causes but in how they motivate. The former, homeostatic, kind motivates in virtue of negative hedonic feelings or aversion; the latter, situational or cognitive, kind does so in virtue of positive hedonic feelings or the attraction to the anticipated pleasure of feeding.

However, although homeostatic and situational or cognitive cues may cause our being motivated to eat independently from one another, it is also widely acknowledged that they typically concur and interact in many ways to cause and causally sustain our motivation to eat. ${ }^{10}$ The tendency to discuss states like hunger for contrastive purposesexplaining how as 'mere' urges they differ from desires and emotions-has led to a neglect of the interplay between these kinds of affect. Tomkins (1995), one of the founders of affective sciences, famously warned against this sort of compartmentalisation within the realm of affective motivation, arguing that it obscures the fact that affective reactions such as pain, hunger and sexual arousal borrow much of their power to motivate from the emotional reactions they tend to 'recruit'"1:

"The panic of one who experiences the suffocation of interruption of his vital air supply has nothing to do with the anoxic drive signal per se. A human being could be, and often is, terrified about anything under the sun. It [is] a short step to see that excitement [has] nothing per se to do with sexuality or with hunger, and that the apparent urgency of the drive system was borrowed from its co-assembly with appropriate affects [emotional reactions] as necessary amplifiers." (Tomkins 1995, p. 32, italics added).

To appreciate Tomkins' point, it might be useful again to consider pain. Although pain is inherently motivating, emotional reactions such as fear and anxiety often contribute to the way pain motivates. ${ }^{12}$ This might not be apparent if we consider only cases in which avoidant behaviour doesn't outlast its cause, as when we immediately withdraw our hand from a hot stove. Consider, however, cases in which the painful sensation continues after the noxious stimulus is removed. In such cases, we still feel motivated to protect the body part where the painful sensation is localised, say by preventing impact against other objects. Now, we might think that this avoidant behaviour is motivated simply by awareness of the painful sensation plus the belief that it would be exacerbated by impact. However, besides being rather implausibly intellectualistic, this view, we feel, fails to fully accommodate the phenomenology of pain-related avoidance and protection. Pain is scary: when in pain we tend to become anxious about the possibility of exacerbating

\footnotetext{
${ }^{10}$ See e.g. Sternson and Eiselt (2017).

11 See also Izard (1977) for more detailed elaboration of this 'recruiting' relation as well as other drive-emotion interactions.

12 See Vlaeyen and Linton (2000) and Leeuw et al. (2007) for a review of relevant literature in the medical sciences.
} 
the painful sensation and our fear and anxiety themselves directly motivate careful avoidant and protective behaviour with no need for mediating cognitions. Moreover, fear and anxiety enhance our attention to the painful sensation. This idea fits well with empirical research showing that (excessive) attention to painful sensations is fed by fear and anxiety, and relatedly, that fear and anxiety crucially contribute to the experience of pain and play a role in its becoming chronic. ${ }^{13}$ This suggests that pain on the one hand and fear and anxiety on the other can be mutually reinforcing.

Something similar is going on, we suggest, in the case of hunger. Except, whereas pain typically recruits negative or aversive emotions such as fear and anxiety, hunger typically recruits positive emotion, namely affective interest and excitement about food (Tomkins 1995; Izard 1977) and the felt attraction we call appetite. The emotional reactions recruited by pain contribute to the biological function of pain by enhancing the agent's aversion to the noxious stimulus. In recruiting positive affect, hunger adds to the agent's existing felt aversion to her present state of need a positive attraction to something that will meet that need, so that she is simultaneously 'pushed' and 'pulled' in the same direction, by the urge to eat and the desire for some specific food respectively.

When we are hungry, normally, we feel not only an aversion to our present state of deprivation but an interest in and attraction to food, to eating. Food is intrinsically appealing. This attraction, like hunger, involves a distinctive modulation of attention. In hunger, our attention is engaged by the sense of deficit; in attraction, by food-related cognition. This typically involves some sense of what kind of food we fancy and mental activities such as fantasising about food and thoughts about how to get it. Such thoughts and fantasies are often (momentarily) rewarding: we look forward to the pleasures of eating, and look forward to them with pleasure, not just with pain at our present state of deprivation. ${ }^{14}$

As with pain, the drive-based affective reaction and the (in this case positive) emotional reactions are mutually reinforcing-they fuel one another. Hunger, by enhancing our sensitivity to food-related stimulation (the taste, sight, smell of food), fuels our interest, excitement and desire for food. At the same time, these emotional reactions, in the absence of food, and once their momentary reward has waned, tend to sharpen our sense of deficit.

This completes our account of how hunger motivates. This account recognises and clearly articulates hunger's distinctive aversive character as a drive-based affective

\footnotetext{
${ }^{13}$ Goubert et al. 2004; Keogh et al. 2001; Peters et al. 2000; Van Damme et al. 2006

14 See Railton (2012) for an illuminating discussion of this kind of positive affective desire.
}

reaction whilst also accommodating the hedonic ambiguity of the hungry agent's state of mind, through an analysis of the complex dynamic interplay between hunger itself and positively valenced, cognitively sophisticated affective reactions. In doing so, we hope to have shown that while it may be important to distinguish different kinds of affect, this shouldn't lead us to treat them in complete isolation from one another. If our aim is to understand the affective and motivational structure of the minds of human agents, the most relevant units of analysis in view of such aim may sometimes be certain dynamic complexes of different kinds of affect that outstrip common taxonomical boundaries. ${ }^{15}$

In the final section, we will conclude by briefly illustrating how our account might further be put to work to capture the variable and complex hedonics of satisfaction and frustration in the experience of the hungry agent.

\section{The Pleasures and Pains of Hunger}

Even though the bodily sensations of hunger may be much the same, being hungry feels different to the agent who expects their urge to be satisfied and to the agent who lacks this expectation, or who expects it to remain unsatisfied. Also, for the agent who expects food there's a big difference depending on whether they expect mere satiation of hunger or satisfaction of appetite. The way in which hunger recruits and interacts with emotion underpins the distinctive pleasures of satisfaction and the anticipation of satisfaction in contrast with mere relief and alleviation of discomfort. And the character of hunger as a felt need explains why it can, when unmet, become a kind of suffering more severe than that caused by the frustration of ordinary desiring. In this final section we offer a brief overview of these different scenarios.

The fulfilling of one's urge, the meeting of one's felt need for food, is called satiation. Satiation is felt as the alleviation of a state of deprivation and hence as a kind of relief. One can feel this pleasure, in as much as it is a pleasure, without enjoying what one eats in order to meet one's felt need. The desire for a particular kind of food, on the other hand, usually results, when fulfilled, in pleasure in the food itself, in eating with pleasure. Such pleasure is not just relief or satiation but is the pleasure of positive affective engagement characterising states such as delight, interest and excitement. After eating, we may either feel a lingering pleasure or, possibly, a persisting desire for more: although you may enjoy your first piece of cake a great deal, it might not be enough

\footnotetext{
15 In this, we agree with Borghini 2017, who emphasises that in order to capture the complexity of our topic we must be wary of treating hunger and appetite in isolation from each other.
} 
to satisfy you. This satisfaction of one's desire for food is not wholly separate from the satiation of one's hunger, but neither do they always perfectly coincide-hence we often keep eating even after we are full.

While the pleasures of eating themselves go beyond the mere relief of satiation, nonetheless one of the ways in which hunger interacts with the desire for food-a way familiar to any gourmand-is that hunger tends to enhance the pleasure of eating. It may be nice to eat a delicious treat even when you aren't particularly hungry, but it is typically better when you are. It is therefore not uncommon to conceive a desire for some foodstuff and to wait until one has an appetite in order to enjoy it the better, perhaps in the mean time looking forward to the future pleasure.

The pleasures and pains of hunger and appetite can also come apart in the negative dimension, and the frustration of hunger and the frustration of the desire for food each have a different affective character. It is not uncommon to have one's hunger satiated by food that one does not find particularly appealing. If you find yourself in such a situation having been looking forward to something more enjoyable, you might feel satiated, but also disappointed, this ambivalent affective situation reflecting the fact that while your need was met, your desire was not. Similarly-although perhaps less commonly-your desire for food might be almost wholly satisfied by, say, an haute cuisine tasting menu, even though you leave the restaurant still feeling a little peckish.

More seriously, and more darkly, hunger is a felt urge based in a real physiological need, which when unmet becomes more and more intense. The frustration of hunger is therefore unlike that of a simple attraction. When a felt attraction goes unsatisfied, the frustration can be felt as a kind of pain, a pain which, when there is still some prospect of satisfaction, further motivates the activity of seeking satisfaction (cf. Munoz-Dardé 2016). Nonetheless, it is generally an option to simply give up and accept defeat, leaving one with a more or less momentary disappointment. By contrast, when the frustrated motivation is dependent on a real need, as hunger is, giving up is not an option: the motivation and the associated negative affect will tend to intensify. If the agent can see no way towards meeting the need, their experience will be one not of mere disappointment but, if the need is profound enough, despair and desperation.

\section{Funding Open access funding provided by University of Geneva.}

Open Access This article is licensed under a Creative Commons Attribution 4.0 International License, which permits use, sharing, adaptation, distribution and reproduction in any medium or format, as long as you give appropriate credit to the original author(s) and the source, provide a link to the Creative Commons licence, and indicate if changes were made. The images or other third party material in this article are included in the article's Creative Commons licence, unless indicated otherwise in a credit line to the material. If material is not included in the article's Creative Commons licence and your intended use is not permitted by statutory regulation or exceeds the permitted use, you will need to obtain permission directly from the copyright holder. To view a copy of this licence, visit http://creativecommons.org/licenses/by/4.0/.

\section{References}

Anscombe GEM (1963) Intention, 2nd edn. Basil Blackwell, Oxford Baynes JW, Dominiczak MH (2014) Medical Biochemistry, 4th edn. Saunders, Cambridge MA

Borghini A (2017) Hunger. In: Kaplan DM (ed) Encyclopedia of Food and Agricultural Ethics, 2nd edn. Springer, New York USA

Christensen NJ, Alberti KG, Brandsborg O (1975) Plasma catecholamines and blood substrate concentrations: Studies in insulin induced hypoglycaemia and after adrenaline infusions. Eur J Clin Invest 5:415-423

Corrall RJ, Frier BM, Davidson NM et al (1983) Cholinergic manifestations of the acute autonomic reaction to hypoglycaemia in man. Clin Sci 64:49-53

Date Y, Kojima M, Hosoda H et al (2000) Ghrelin, a novel growth hormone-releasing acylated peptide, is synthesized in a distinct endocrine cell type in the gastrointestinal tracts of rats and humans. Endocrinology 141:4255-4261

Deonna J, Teroni F (2012) The Emotions: A philosophical introduction. Routledge, London

Frijda NH (1986) The Emotions. Cambridge University Press, Cambridge

Frijda NH (2007) The Laws of Emotion. Routledge, London

Gnanapavan S, Kola B, Bustin SA et al (2002) The tissue distribution of the mRNA of ghrelin and subtypes of its receptor, GHS-R, in humans. J Clin Endocr Metab 87:2988-2991

Goubert L, Crombez G, Van Damme S (2004) The role of neuroticism, pain catastrophizing and pain-related fear in vigilance to pain: a structural equations approach. Pain 107(3):234-241

Grahek N (2001) Feeling Pain and Being in Pain. BIS-Verlag, University of Oldenburg, Oldenburg

Heller SR, Macdonald LA, Herbert M et al (1987) Influence of the sympathetic nervous system on hypoglycaemic warning symptoms. Lancet 11:359-363

Izard CE (1977) Human Emotions. Springer Science+Business Media, New York

Johnston M (2001) The authority of affect. Philos Phenomen Res 63(1):181-214

Keogh E, Ellery D, Hunt C et al (2001) Selective attentional bias for pain-related stimuli amongst pain fearful individuals. Pain 91(1-2):91-100

Kim MS, Yoon CY, Park KH et al (2003) Changes in ghrelin and ghrelin receptor expression according to feeding status. NeuroReport 14:1317-1320

Kojima M, Hosoda H, Date Y et al (1999) Ghrelin is a growthhormone-releasing acylated peptide from stomach. Nature 402:656-660

Leeuw M, Goossens ME, Linton SJ et al (2007) The fear-avoidance model of musculoskeletal pain: current state of scientific evidence. J Behav Med 30(1):77-94

Mandler G (1975) Mind and Emotion. Wiley, New York

Melzack R, Casey KL (1968) Sensory, motivational, and central control determinants of pain: a new conceptual model. In: Kenshalo D (ed) The Skin Senses. C. C. Thomas, Springfield

Mulligan K (2007) Intentionality, knowledge and formal objects. Disputatio 2(23):1-24

Munoz-Dardé V (2016) Puzzles of regret Philos Phenomen Res 92(3):778-784 
Nash RA (1989) Cognitive theories of emotion. Noûs 23(4):481-504

Peters ML, Vlaeyen JW, van Drunen C (2000) Do fibromyalgia patients display hypervigilance for innocuous somatosensory stimuli? Application of a body scanning reaction time paradigm. Pain 86(3):283-292

Ploner M, Freund H-J, Schnitzler A (1999) Pain affect without pain sensation in a patient with a postcentral lesion. Pain 81:211-214

Prinz JJ (2004) Gut reactions: A perceptual theory of emotion. Oxford University Press, Oxford

Railton P (2012) That obscure object, desire. Proceedings and Addresses of the American Philosophical Association 86(2):22-46

Reisenzein R, Schönpflug W (1992) Stumpf's cognitive-evaluative theory of emotion. Am Psychol 47(1):34-45

Scanlon TM (1998) What we owe to each other. Harvard University Press, London

Scarantino A. (2005) Explicating Emotions. Dissertation, University of Pittsburgh.

Sherrington C (1900) Cutaneous sensations. In: Schäfer EA (ed) Textbook of Physiology. Pentland, London

Smith M (1987) The humean theory of motivation. Mind 96(381):36-61

Soteriou M (2013) The mind's construction: The ontology of mind and mental action. Oxford University Press, Oxford

Soteriou M (2018) The ontology of emotion. In: Naar H, Teroni F (eds) The ontology of emotions. Cambridge University Press, Cambridge
Sternson SM, Eiselt A-K (2017) Three pillars for the neural control of appetite. Annu Rev Physiol 79(1):401-423

Tomkins SS (1995) Exploring affect: The selected writings of Silvan S Tomkins. Cambridge University Press, Cambridge

Toshinai K, Mondal MS, Nakazato M et al (2001) Upregulation of ghrelin expression in the stomach upon fasting, insulin-induced hypoglycemia, and leptin administration. Biochem Bioph Res Co 281:1220-1225

Van Damme S, Crombez G, Hermans D et al (2006) The role of extinction and reinstatement in attentional bias to threat: A conditioning approach. Behav Res Ther 44(11):1555-1563

Vlaeyen JW, Linton SJ (2000) Fear-avoidance and its consequences in chronic musculoskeletal pain: a state of the art. Pain 85(3):317-332

Wilson JRS (1972) Emotion and object. Cambridge University Press, Cambridge

Publisher's Note Springer Nature remains neutral with regard to jurisdictional claims in published maps and institutional affiliations. 